\section{ACUTE DILATATION OF THE STOMACH}

BY

\section{HAMILTON BAILEY, F.R.C.S. \\ Surgeon, Royal Northern Hospital}

Experience has taught me that acute dilatation of the stomach is a fairly common post-operative complication. It can occur after any operation. In the older literature operations upon the biliary tract headed the list. For some reason or another this does not appertain at the present time. Possibly the greatest incidence follows prostatectomy, but from time to time acute dilatation of the stomach is encountered after such divergent surgical procedures that nothing profitable is likely to accrue from enumerating them. The main object of this communication is to stress the need for early diagnosis, and the practical aspects of the problem will be discussed first.

\section{Diagnosis}

Acute dilatation of the stomach can be diagnosed before the patient vomits. The day should have passed when the condition remains unsuspected until an enormous quantity of the characteristic fluid, which may be likened to the storm water of a peat-laden stream, is ejected.

PREMONITORY SYMPTOMS AND SIGNS

Early symptoms and signs are far from being stereotyped. We are summoned to the bedside because there is something amiss. The pulse is rising. The patient need not look gravely ill. He is not in any pain, but he usually says that he feels uncomfortable. It is of paramount importance to realize that vomiting occurs relatively late. Let alone vomiting, at this stage he does not necessarily experience even nausea, but an occasional hiccup is not uncommon. The output of urine is invariably scanty, although during the first few hours this fact cannot be gauged with accuracy. On observing the upper abdomen carefully a slight fullness may be seen in the hypochondria ; the characteristic sign is the obliteration of that normal sulcus immediately beneath the costal margin (Fig. 1), but in obese subjects this is difficult to assess, if not entirely unreliable.

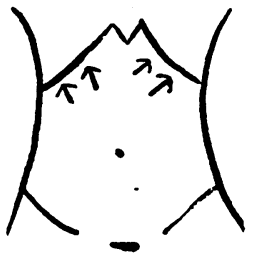

Fig. 1 .

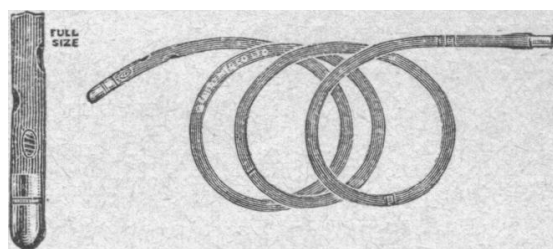

FIG. 2.
FIG. 1.-Obliteration of the normal slight concavity beneath the costal margin is a somewhat characteristic sign in acute dilatation of the stomach.

FIg. 2.-My tube for continuous aspiration of the stomach via the nasal route. There is a coiled spring within the distal end of the tube to stiffen it. This aids considerably in its passage from the nostril to the stomach.

Even if the diagnosis of acute dilatation is merely on the horizon, no possible harm can accrue from what may be termed "sounding the stomach." The nasal route for the passage of the tube is the best. A Ryle tube can be used, but the one illustrated in Fig. 2 is a little easier to pass, for it contains a coiled spring in the distal end, which helps to stiffen the tube. At the Royal Northern Hospital I learned from Sister McClusky, who is an adept at this procedure, a very simple and efficient technique. The tube is first placed in ice-cold water. After the end has been passed down the nose and made to enter the nasopharynx the patient is given sips of water. With each gulp the tube is passed onwards until it is well within the stomach (Fig. 3). The contents are then aspirated with a well-fitting syringe, preferably glass.

I used to be afraid of distressing the patient by sounding the stomach, especially when the diagnosis was in reasonable doubt ; but so often has the benefit from the passage of the tube outweighed the misdirected compassion of withholding it that I feel most strongly that to procrastinate even for a few hours is the antithesis of good judgment. Over and over again a quantity

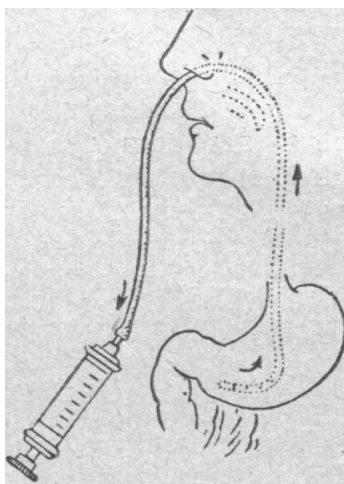

Fig. 3.-Drainage of the stomach via the nose. of dark fluid is aspirated, and the diagnosis of at least some degree of acute dilatation is established. Even if the stomach is found to be empty, extremely important diagnostic data have been obtained.

\section{Principles of Treatment of Acute Dilatation}

These principles are: (1) empty the stomach and keep it empty; (2) administer continuous intravenous saline;

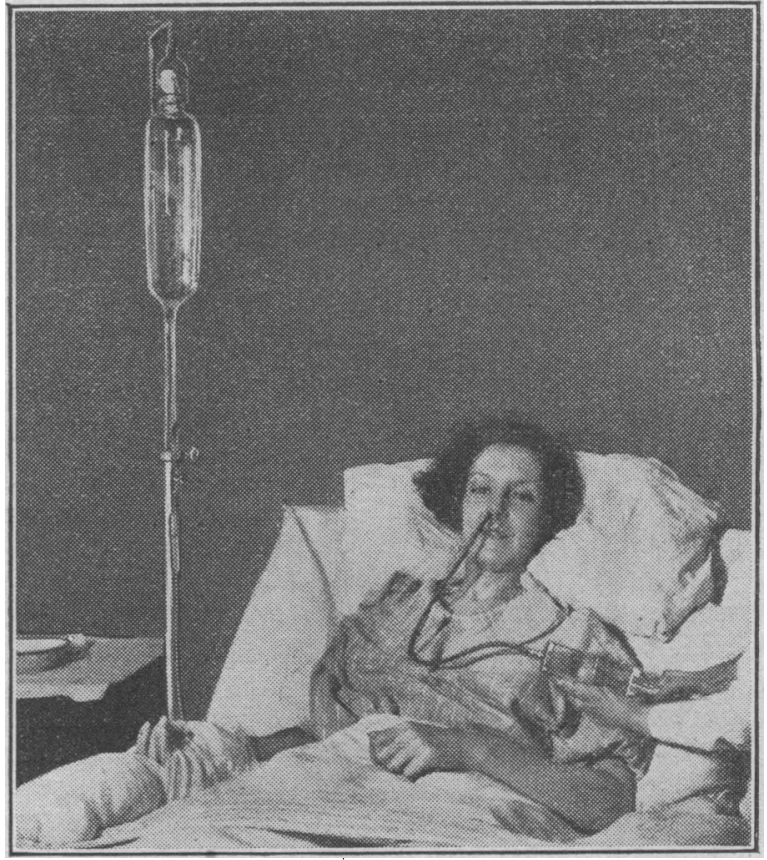

FIG. 4.-Severe acute dilatation of the stomach occurred four hours before this photograph was taken. The patient, the day previously, had the lower jleum resected for Crohn's disease.

(3) invoke the aid of gravity. With the gastric aspiration tube in situ the stomach can be emptied and kept empty. The next important principle is to replenish the fluid loss by giving continuous intravenous saline. Posture, which until recently was given prior place in the treatment, is, I consider, relatively unimportant. This is fortunate, for to be compelled to turn a patient with a laparotomy or suprapubic wound on to his face, and to raise the foot of the bed, is not desirable if it can be avoided. If the 
patient is responding to the first two measures-and usually the response is undeniable - the application of the third is unnecessary. Although I have never used it, the German method of placing the patient in the high Trendelenburg position seems to be more generally applicable than the prone posture with elevation of the foot of the bed.

The fluid aspirated is measured and charted. The patient may drink as he pleases, and the injected fluid is aspirated promptly; in this way the stomach is washed out. Eserine 1/200 grain is prescribed every four hours for three doses. If the case is one of acute dilatation without other complications, signs of improvement are not long delayed. The pulse improves, and the fluid aspirated lessens in quantity and becomes clearer. Even when the fluid aspirated is quite clear (Fig. 4) danger is not passed, for gastric dilatation is prone to recur. The gastric tube should be left in place at least thirty-six hours after the stomach has apparently regained its tone. Before withdrawing the tube it is a good practice to give a "gastric mobility test." I order the patient to drink half a pint of barley-water coloured with cochineal or indigo-carmine. If in an hour and a half none of this coloured fluid can be aspirated, it is proof positive that the stomach has regained its tone; only then is it safe to withdraw the tube and begin feeding.

\section{Theoretical Considerations}

Acute dilatation of the stomach was first described by Kundradt in 1871. In 1872 Hilton Fagge gave an independent description. Much work has been done upon the condition, and many theories have been propounded, but no substantial advance in understanding it has been made

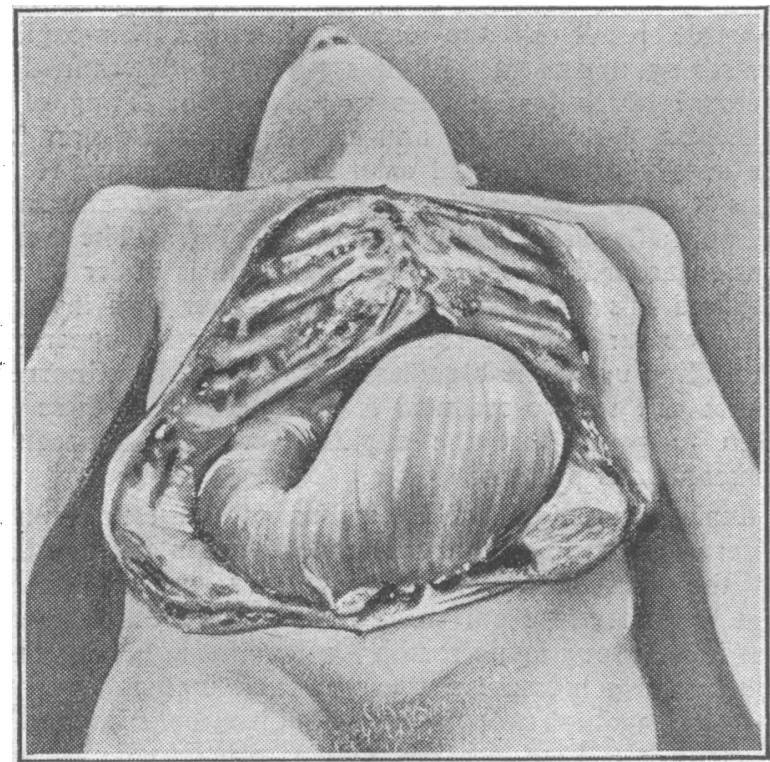

Fig. 5.-Acute dilatation of the stomach seen at necropsy.

in the last twenty-five years. The vomitus has an acid smell, and usually contains black particles. The amount of fluid produced and ejected in acute dilatation is so enormous that for generations inquiring minds have engaged upon the solution of the riddle, "Where does it all come from?" Obviously the vomitus usually contains bile, sometimes even pancreatic fluids can be demonstrated in it, but the greatest part of the production must be attributed to gastric hypersecretion. At necropsy the stomach is found to be enormously dilated and may extend into the pelvis (Fig. 5). In a case reported by Albrecht the greater curvature measured twenty-seven inches and the lesser seven inches, and the pyloric opening two inches. It is important to note that the dilatation usually extends down to the point where the duodenum is crossed by the root of the mesentery. This has been noted by competent observers many times. In one case at least-Baulmer's-the constriction of the mesenteric root was so pronounced that circular necrosis of the mucosa was found. The popular conception is that the dilated stomach pushes down a mass of small intestine, causing in turn a drag upon the mesentery, and this

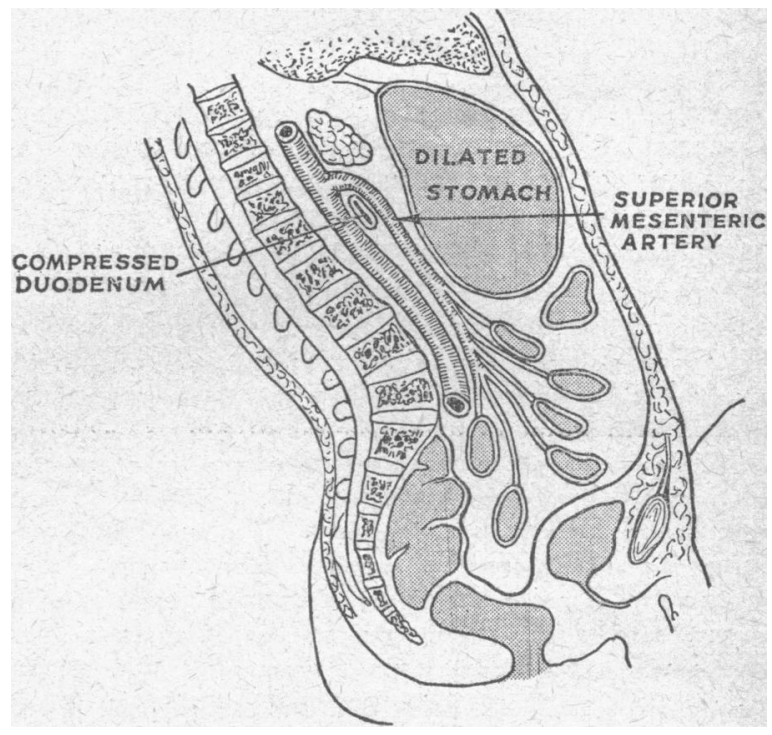

F1G. 6.- The vicious cycle of untreated acute dilatation. The dilated stomach pushes down the small intestine, which drags upon the mesentery, which in turn compresses the third part of the duodenum.

strangles the duodenum (Fig. 6). The initial dilatation has been attributed to vagal shock and to swallowed air. The swallowed-air theory has little to recommend it; indeed, it can be discounted. It is more than probable that primary or delayed shock, particularly with the patient in Fowler's position, would tend to favour gastric dilatation; but, important as it is as a subsidiary factor, this cannot be the whole truth. What causes the initial expansion of the stomach is still a mystery.

\section{Bibliography}

Albrecht. Quoted by H. Hartmann, Presse méd., 1920, 28, 625. Fagge, C. Hilton (1872-3). Guy's Hosp. Rep., 18, 1.

Kundradt. Quoted by H. Hartmann, Presse méd., 1920, 28, 625.

L. Amitrano (Rinasc. med., 1938, 15, 724) records eight cases of argyrosis in newborn children following the local treatment of conjunctivitis by argyrol. The conjunctivitis was catarrhal in four, purulent in two, and gonococcal in two. The argyrosis appeared in one case after more than a month's treatment, in three after a month, and in four after three weeks. The coloration lasted for a few days and gradually subsided within a week. No other symptoms were observed. Many cases of chronic argyrosis have been described in adults following the prolonged ingestion of silver preparations, but the condition is much rarer in infants, though Lavel and Stand have recorded seventy cases, including fifteen of their own, in which argyrosis followed prolonged nasal instillations with organic preparations of silver. 